\title{
Erratum to: On the tangential restitution problem: independent friction-restitution modeling
}

\author{
Antonio Doménech-Carbó
}

Published online: 15 November 2014

(C) Springer-Verlag Berlin Heidelberg 2014

Erratum to: Granular Matter (2014) 16:573-582

DOI 10.1007/s10035-014-0507-3

Unfortunately, a definition of incidence and rebound angles different to that used in all other equations in this paper was written. The correct definition is $\tan \gamma=|\mathbf{u} \times \mathbf{n}| / \mathbf{u} \cdot \mathbf{n}$; $\tan \delta=|\mathbf{v} \times \mathbf{n}| / \mathbf{v} \cdot \mathbf{n}$. Accordingly, Eqs. (17) and (18) should be rewritten as

$$
\begin{aligned}
& R \Omega=R \omega-\left[\frac{5}{7}\left(1+e_{\mathrm{t}}\right)(u \sin \gamma+R \omega)+\frac{5}{2} \mu\left(1+e_{\mathrm{n}}\right) u \cos \gamma\right] \\
& R \Omega=R \omega-\frac{5}{7}\left(2+e_{\mathrm{t}}\right)(u \sin \gamma+R \omega)
\end{aligned}
$$

The online version of the original article can be found under doi:10.1007/s10035-014-0507-3.

A. Doménech-Carbó ( $\varangle)$

Department of Analytical Chemistry, University of Valencia,

Dr. Moliner, 50, 46100 Burjassot, València, Spain

e-mail: antonio.domenech@uv.es 